\title{
Fuel Penalty Comparison for (Electrically) Heated Catalyst Technology
}

\author{
J.T.B.A. Kessels ${ }^{1}$, D.L. Foster ${ }^{1}$ and W.A.J. Bleuanus ${ }^{2}$ \\ 1 TNO Automotive, Steenovenweg 1, P.O. Box 756, 5700 AT Helmond - The Netherlands \\ 2 TeleflexGFI Europe, Edisonweg 50, P.O. Box 380, 4200 A Gorinchem - The Netherlands \\ e-mail: john.kessels@tno.nl -darren.foster@tno.nl - sblevanus@teleflexgfi.com
}

\begin{abstract}
Résumé - Comparaison de l'augmentation de consommation de carburant pour la technologie de catalyseurs chauffés à l'électricité - L'efficacité de conversion des catalyseurs est principalement définie par la gamme de température dans laquelle ils fonctionnent. Un retard du point d'allumage a traditionnellement été utilisé pour réduire le temps d'amorçage du catalyseur. Ceci est cependant associé à une augmentation de la consommation de carburant. Avec l'électrification des véhicules, la possibilité de chauffage électrique représente véritablement une alternative, tout particulièrement pour les véhicules hybrides. Cependant, la complexité des véhicules hybrides rend difficile l'évaluation des technologies de chauffage éventuelles ainsi que l'augmentation de la consommation de carburant associée ; il est aussi difficile de comparer ces résultats à ceux des solutions traditionnelles.

Cette étude évalue l'installation d'un catalyseur chauffé à l'électricité dans un véhicule hybride, équipé d'un moteur au Gaz Naturel (GN). L'effet du chauffage sur le temps d'amorçage et la consommation de carburant est déterminé en utilisant des techniques d'analyse issues de la commande intégrée du groupe motopropulseur. L'importance de cette approche intégrale est illustrée par un cas exemplaire : l'impact d'une stratégie avec chauffage électrique sur la consommation de carburant et sur l'amélioration de l'efficacité de conversion catalytique est comparé à celui d'une stratégie de retard du point d'allumage. Au cours de cette comparaison, données de simulation et d'analyse ont été combinées, créant la base de développements de commandes futurs pour une stratégie d'amorçage adaptée.
\end{abstract}

Abstract - Fuel Penalty Comparison for (Electrically) Heated Catalyst Technology - The conversion efficiency of three way catalytic converters is mainly defined by the temperature range wherein they are operating. Traditionally, ignition retard has been used to reduce the light-off time of the catalyst. This is however associated with a fuel penalty. With increasing vehicle electrification, electrically heating facilities present an alternative, especially for hybrid vehicles. Nevertheless, system complexity of hybrid vehicles prevents engineers to evaluate possible heating technologies and their corresponding fuel penalty with respect to traditional solutions.

This paper evaluates the application of an electrically heated catalyst on a hybrid vehicle equipped with a Natural Gas $(N G)$ engine. The effect of heating power on light-off time and fuel penalty is determined, using analysis techniques emerging from integrated powertrain control. By means of a case study, the importance of an integral approach is explained by comparing the fuel penalty and conversion efficiency improvement of electric heating with that of ignition retard. In this process, a mix of simulation and test data were combined, forming the foundations for future control developments of a suitable light-off strategy. 


\section{NOMENCLATURE}

$\begin{array}{ll}\text { BSFC } & \text { Brake Specific Fuel Consumption } \\ \text { BTDC } & \text { Before Top Dead Centre } \\ \mathrm{CA} & \text { Crank Angle } \\ \mathrm{CO} & \text { Carbon monoxide } \\ \mathrm{CO}_{2} & \text { Carbon dioxide } \\ \mathrm{EHC} & \text { Electrically Heated Catalyst } \\ \text { IPC } & \text { Integrated Powertrain Control } \\ \text { NG } & \text { Natural Gas } \\ \text { NOx } & \text { Nitrogen Oxides } \\ \text { THC } & \text { Total HydroCarbons } \\ \text { TWC } & \text { Three Way Catalyst }\end{array}$

\section{INTRODUCTION}

With growing concerns about the environment and energy security, the automotive industry faces enormous challenges to find an optimal, cost-efficient balance between driveability and fuel efficiency within the boundaries set by emission legislation, as illustrated in Figure 1, see also [1,2].

A major driver is the proposed European legislation on $\mathrm{CO}_{2}$ emissions, along with the future stringent emissions requirements. In order to achieve these requirements in a cost effective and timely manner, TNO is actively researching, together with partners, the potential of Integrated Powertrain Control (IPC).

Basically speaking, the integral system approach of IPC falls apart into two main topics. The first topic entails selection and design of the optimal powertrain configuration. The second topic focuses on control strategies, exploiting synergy between subsystems and offering the highest overall performance of the final powertrain configuration.

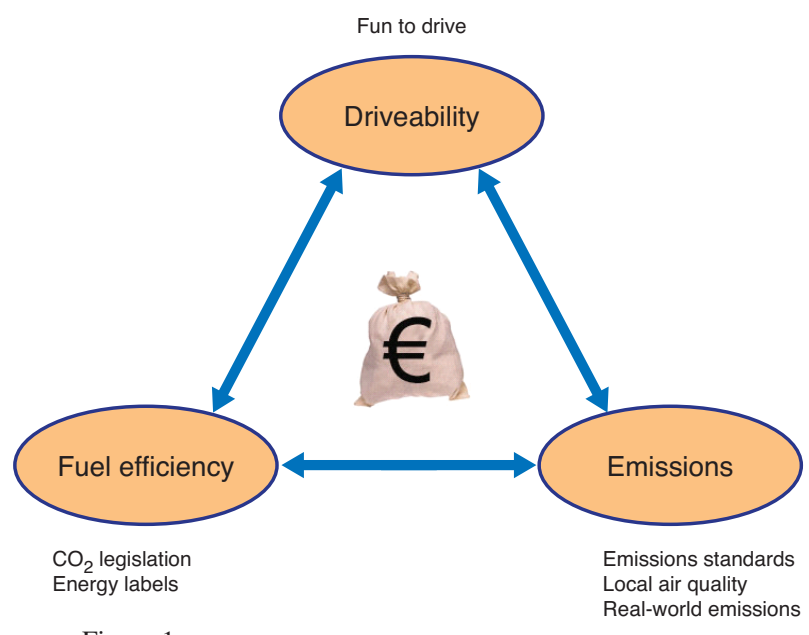

Figure 1

Challenges of automotive industry.
This paper deals with the first topic and presents a calculation method for comparing the fuel penalty of different catalyst heating methodologies. Since the conversion efficiency of catalytic converters is temperature dependent, fast catalyst heating offers an effective manner to minimize the catalyst light-off time and hence, reduce exhaust emissions from cold start. On the other hand, offering additional heat to the catalyst leads to more energy consumption and typically relates back to additional fuel consumption. Various implementations exist for catalyst heating. However, deciding which technology should preferably be used is far from trivial. The calculation method presented in this paper offers an effective tool in this decision process.

By means of an illustrative example based on a hybrid electric vehicle with natural gas engine, two heating methods are analyzed for the Three Way Catalyst system: engine calibration through ignition retard versus the electrically heated catalyst. Both solutions come with an additional fuel penalty and it will be shown how to calculate the equivalent fuel consumption for making a fuel-efficient trade-off between both heating concepts.

This paper is build up as follows. Section 1 provides a short introduction to IPC and further details the scope of this paper. The impact of a suitable light-off strategy for emission control is illustrated in Section 2. The case study in Section 3 explains how to calculate the corresponding fuel consumption when additional heat is offered to the catalyst system. Finally, the conclusions are stated in Section 4.

\section{INTEGRATED POWERTRAIN CONTROL}

The IPC concept involves a complete approach for analysis, simulation, testing and control. Emission and energy management are seen as integral and connected aspects of the vehicle powertrain system. Optimisation is performed across sub-system boundaries within vehicle functions. Whereas energy management minimizes the primary energy usage of the vehicle, emission management optimizes the exhaust gas emissions. Thermal management encompasses the thermal aspect of energy management, including exhaust and coolant enthalpies. Consequently, thermal management relates to energy management in view of reducing fuel consumption, but it also relates to emission management for reducing exhaust gas emissions. It is clear that all these optimization tasks cannot be solved independently. Moreover, a unified framework is needed to deal with all vehicle requirements and simultaneously satisfy constraints on fuel economy, emissions, driveability, reliability, and hardware costs. This is graphically shown in Figure 2.

Hybrid powertrains provide additional freedom for optimisation of energy flows in the vehicle through the possibility of recovering and buffering large amounts of energy. While this functionality is often used for reducing fuel 


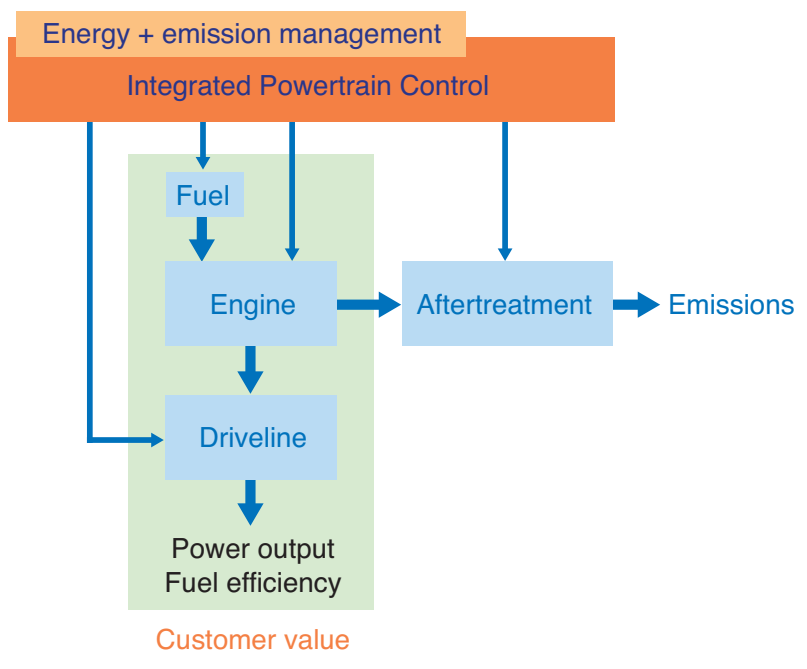

Figure 2

Interaction of IPC with vehicle powertrain.

consumption and increasing vehicle performance, it may also be applied to reducing emissions. However, the emissions reduction/fuel consumption trade-off of such techniques need to be compared with conventional measures to identify potential performance improvements and the suitability of such techniques for future $\mathrm{CO}_{2}$ and emissions requirements.

\section{EMISSION CONTROL}

Generally speaking, the raw engine-out emissions for a stoichoimetric Otto engine are relatively high. In order to achieve low levels of emissions as demanded by stringent emission legislation, a Three Way Catalyst (TWC) is generally applied, which proves particularly effective with appropriate engine mixture control.

\subsection{Light-Off Temperature}

The conversion efficiency of a TWC heavily depends on the temperature of the catalyst. At ambient temperature (e.g. after cold start), the catalyst activity is low leading to a high level of slip. To achieve good conversion efficiency, the catalyst temperature needs to be above light-off temperature, i.e. the point where the catalyst reaches $50 \%$ conversion efficiency. In this work, the focus is on Natural Gas (NG) engines with emphasis on Total HydroCarbon (THC) light-off temperature. Typically THC light-off is achieved when the catalyst input temperature reaches approximately $300^{\circ} \mathrm{C}$. Above this temperature, the catalyst conversion efficiency rapidly increases leading eventually to low levels of tail-pipe out emissions.
Absolute tail-pipe emissions depend largely on the time $t_{L}$ (s) to reach this light-off temperature. Figure 3 shows an illustrative example of a THC light-off profile for an NG TWC, measured at a constant engine operating point with $\lambda=1.02$ fixed. There should be noted that the conversion of $\mathrm{CH}_{4}$ into $\mathrm{CO}_{2}$ and $\mathrm{H}_{2} \mathrm{O}$ is far more difficult, compared with that of other oxidation reactions. This makes THC conversion efficiency dominant when considering aftertreatment requirements for NG stoichiometric engines.

A stock catalytic converter has a light-off period in the order of 1-2 minutes [3] and especially the THC conversion efficiency remains low during this heating phase. By means of a suitable light-off strategy, the light-off period can be reduced and consequently emissions will reduce. Additionally, the cold start phase of engine operation has a significant influence on fuel consumption, typically $10-15 \%$ on the standard European drive cycle. This implies that special attention for the light-off strategy is an important factor for keeping fuel consumption low while achieving further emissions reductions. Conversely, a dedicated light-off strategy can also be used to achieve similar tail-pipe emissions whereas the catalyst volume, precious metal loading or other costs decrease. IPC will be an effective tool to develop a strategy which includes all these requirements simultaneously.

\subsection{Light-Off Strategy}

The goal of the light-off strategy is to reduce light-off time while minimizing emissions and fuel consumption. Offering additional heat to the TWC brings the catalyst faster to its light-off temperature and less tail-pipe emissions are produced for THC, NOx and CO. The net emission reduction can be approximated by considering the average mass flow

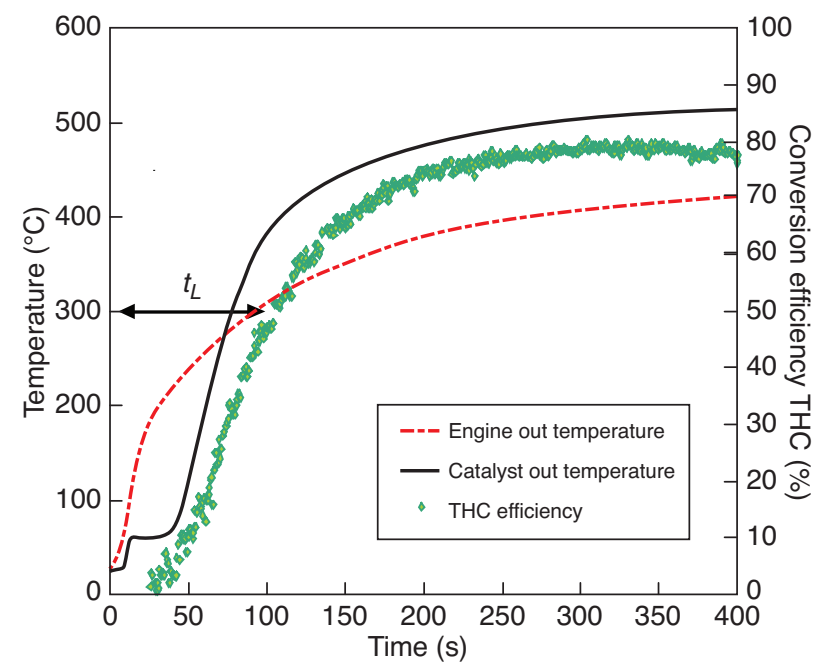

Figure 3

Typical light-off profile of a TWC at $\lambda=1.02$. 
before and after light-off time $t_{L}$. Suppose the average mass flow of emission $x \in\{\mathrm{THC}, \mathrm{NOx}, \mathrm{CO}\}$ during the light-off period is given by $\dot{m}_{\text {pre_L }}^{x}[\mathrm{~g} / \mathrm{s}]$. Similarly, the average mass flow after light-off period is denoted by $\dot{m}_{\text {post } L}^{x}[\mathrm{~g} / \mathrm{s}]$, see Figure 4 . This behavior is typically seen on official test cycles such as the New European Driving Cycle.

With an improved light-off strategy, the catalyst reaches its light-off temperature at $t_{L H}<t_{L}[\mathrm{~s}]$ and the emission reduction is approximately equal to (see also Fig. 4):

$$
m_{H}^{x} \approx\left(\dot{m}_{\text {post } \_L}^{x}-\dot{m}_{\text {pre_L }}^{x}\right)\left(t_{L}-t_{L H}\right)[\mathrm{g}]
$$

To achieve this reduction in light-off time, a multitude of measures are possible, including:

- insulation of exhaust, e.g. double-walled tubing;

- close coupled catalyst;

- exhaust gas temperature control;

- Electrically Heated Catalyst (EHC).

Exhaust gas temperature control is commonly performed by ignition retard combined with close coupled catalysts. By retarding the ignition, exhaust temperature is increased which leads to faster heat transfer to the catalyst, reducing light-off time. This method has proven to be highly effective, see e.g. [4]. One disadvantage is the increase in fuel consumption that results due to lower engine efficiency.

An alternative for ignition retard to increase the exhaust gas temperature is electric heating of the catalyst. Heating methods fall apart into two categories:

- direct heating of the catalyst, where the catalyst substrate is used as a heating element;

- indirect heating of the catalyst, where the heating element is placed upstream of the catalyst. Exhaust gases are heated, leading to indirect heating of the catalyst.

A hybrid electric vehicle offers various mechanisms to supply the electric energy needed for catalyst heating:

- directly by the electric generator in the powertrain;

- from the battery, using regenerative braking energy;

- from the battery, using energy that is recharged by the generator.

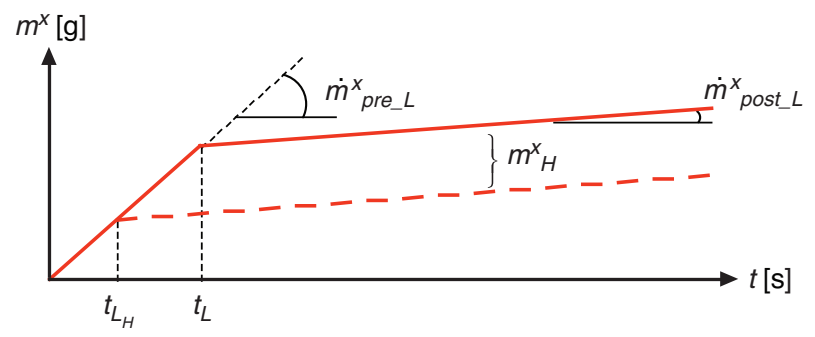

Figure 4

Emission reduction with reduced light-off time.
All these charging methods lead to fuel penalties compared to a hybrid powertrain without EHC, as energy used by the EHC cannot be used for other fuel-saving functions from a hybrid vehicle (e.g. boost functionality).

In order to evaluate the effectiveness of catalyst heating by means of ignition retard as well as EHC, TNO has developed IPC-tools to quantify the fuel penalty regarding both heating methods. This will be illustrated by a case study in the next section.

\section{CASE STUDY}

The focus of this study is on comparing engine ignition retard with electric catalyst heating from an IPC perspective for an NG stoichiometric Otto engine in a hybrid vehicle application.

Measurements with an NG engine and a TWC are used to obtain insight into the heating behavior of the catalyst. These measurements included the effect of adjusting the ignition retard. For investigations into the effect of the EHC, simulations were used. The catalyst was simulated using TNO's catalyst model, SimCat [5]. Exhaust data from measurements were used to fit this catalyst model. SimCat entails a physical model description of the catalyst where consecutive segments split up the catalyst in axial direction. Each segment includes a temperature model and a conversion efficiency model. The temperature model is based on energy balances for the gas and solid phase. The efficiency model calculates the catalyst activity in terms of $\mathrm{HC}, \mathrm{CO}$ and NOx emissions. The temperature model and the efficiency model are interconnected according to Figure 5.

\subsection{Ignition Retard}

To investigate the trade-off between fuel consumption and light-off time for ignition retard, tests were performed on a 5 cylinder, 2.3L NG MPFI (Multi-Point Fuel Injection)

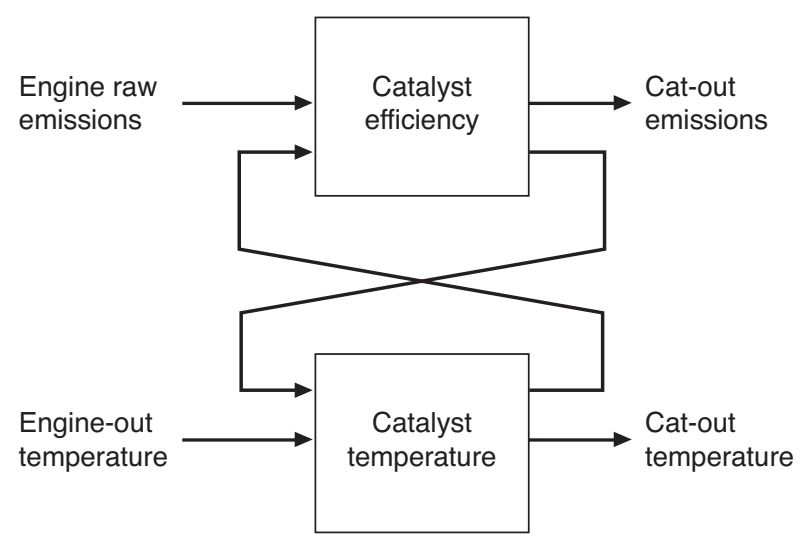

Figure 5

Simcat TWC model overview. 


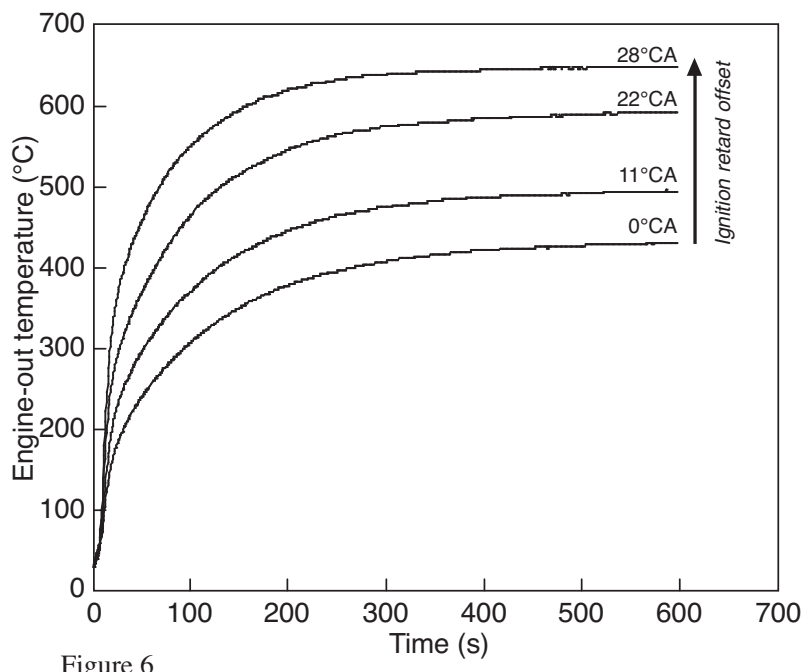

Figure 6

Temperature increases with ignition retard.

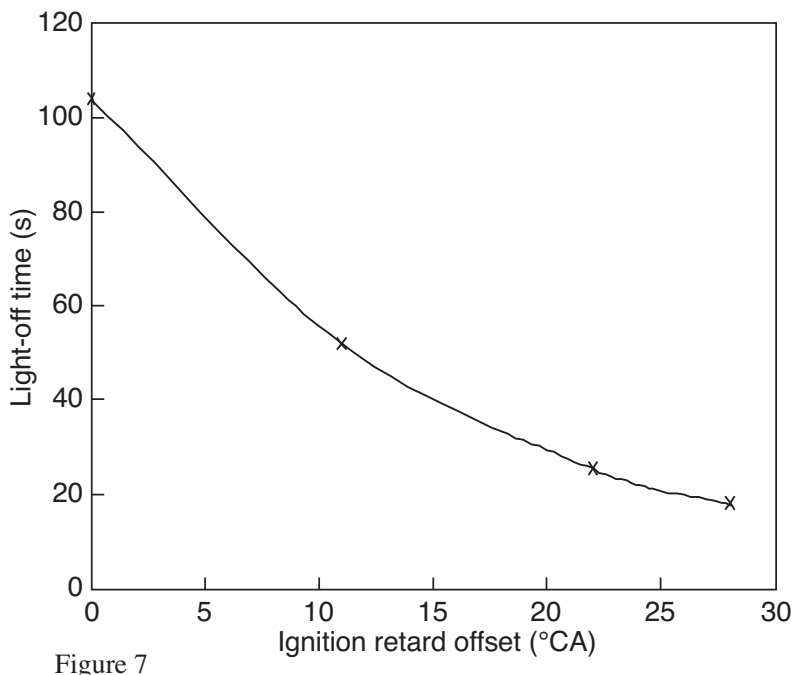

Light-off time reduction with ignition retard.

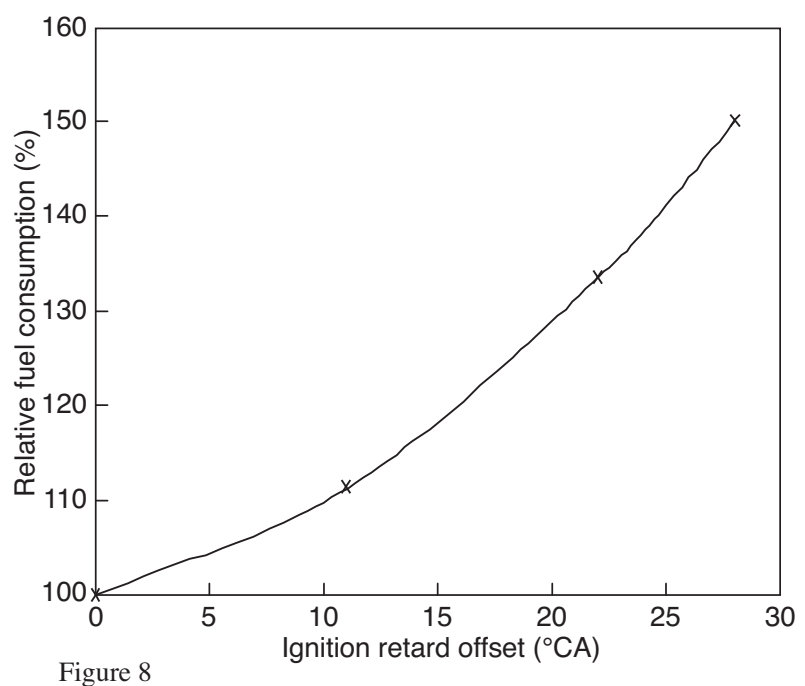

Figure 8

Measured fuel penalty for ignition retard. engine running on Dutch NG. The engine was running constant at 2 bar BMEP, $2000 \mathrm{rpm}$ and $\lambda=1.02$. Exhaust gas temperature, catalyst temperature and fuel consumption were measured at the ignition retard values $\varphi$ [degrees of Crankshaft Angle (CA)] shown in Table 1. Retard was set as an offset relative to the standard ignition advance of 25 degrees Before Top Dead Centre (BTDC), in order to take into account the default engine calibration during warming up process. The measured engine out temperatures are shown in Figure 6.

TABLE 1

Ignition retard measurement data

\begin{tabular}{c|c|c|c}
\hline Test & $\begin{array}{c}\text { Ignition retard } \\
\text { (re 25 } 5^{\circ} \mathrm{CA} \text { BTDC) }\end{array}$ & $\begin{array}{c}\text { Fuel } \\
\text { mass flow }(\mathrm{g} / \mathrm{s})\end{array}$ & $\begin{array}{c}\text { Relative } \\
\text { fuel use (\%) }\end{array}$ \\
\hline 1 & 0 & 0.91 & 100 \\
\hline 2 & 11 & 1.01 & 111 \\
\hline 3 & 22 & 1.22 & 134 \\
\hline 4 & 28 & 1.37 & 150 \\
\hline
\end{tabular}

As indicated in Figure 7, the increased engine out temperature from ignition retard has significant effect on the lightoff time. By applying ignition retard, reduction in engine torque is foreseen because its thermal efficiency decreases. To achieve 2 bar BMEP, the throttle valve moves to a more open position and the intake airflow increases. A laminar flow element is used to measure this intake airflow. The corresponding fuel mass flow $\dot{m}[\mathrm{~g} / \mathrm{s}]$ is calculated by using the signal from the wideband lambda sensor. These values are also indicated in Table 1. A substantial increase in fuel consumption can be observed, up to 50\% (see also Fig. 8).

According to the fuel mass flow $\dot{m}$, the additional fuel penalty from ignition retard can be characterized by the following formula:

$$
\psi(\varphi)=\dot{m}(\varphi)-\dot{m}(\varphi=0)[\mathrm{g} / \mathrm{s}]
$$

By assuming that ignition retard is only active during the light-off period, the additional fuel penalty can be approximated by:

$$
F_{R}(\varphi) \approx \int_{0}^{t_{L}(\varphi)} \psi(\varphi) d t[\mathrm{~g}]
$$

This fuel penalty $F_{R}(\varphi)$ is shown in Figure 9. In the next section, a similar figure will be drawn for EHC. All this information enables IPC to make a fair comparison between the fuel penalty from both heating mechanisms.

\subsection{Electrically Heated Catalyst}

To evaluate the potential of the EHC, the catalyst was simulated using SimCat. This catalyst model includes energy balances for the gas phase as well as the solid catalyst bed (substrate with washcoat). This allows for simulations with both direct 


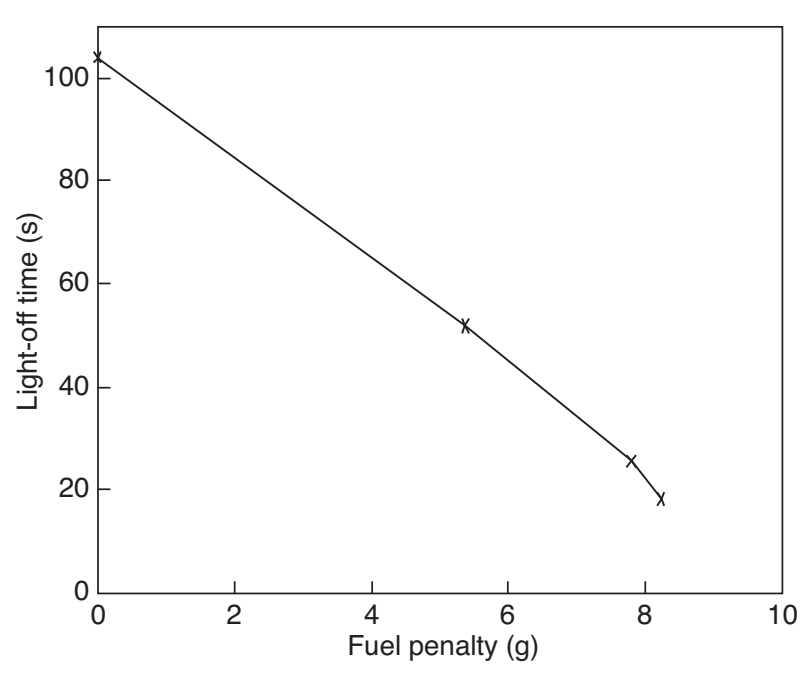

Figure 9

Fuel penalty $F_{R}$ from ignition retard.

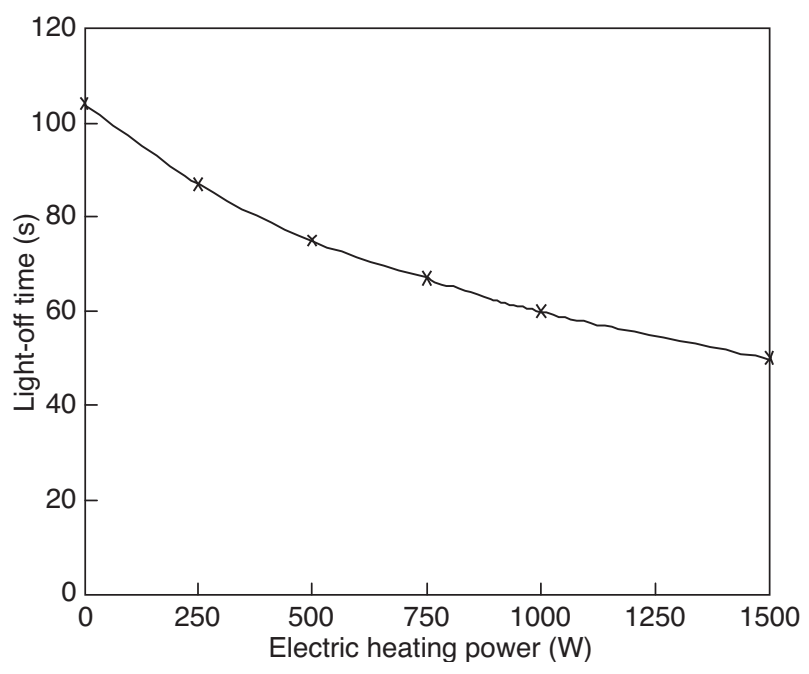

Figure 10

Light-off time reduction with EHC. as well as indirect heating. Nevertheless, this paper presents only results using direct heating. More specifically, the electric heating is only applied to the first catalyst segment of the Simcat model. This is a cost effective solution where a relatively low heating power is required to reach light-off temperature. Since only a small mass is heated, the catalyst reaches light-off temperature very quickly. This enables fast startup of exothermal reactions (mainly from HC oxidation) to assist with heating up the remainder of the catalyst, see also [6]. Note that the catalyst model includes energy balances for both the gaseous phase and the solid phase. These energy balances describe the heat transfer from convection, conduction and reaction heat. Thermal energy from electric heating is directly offered to the solid phase.

The light-off time as a function of electric power is shown in Figure 10. In this case study, the EHC has a relatively modest electric power demand, compared to the power requirements for hybrid vehicle application (e.g. electric driving). Application of the EHC at higher power levels is possible, but is not considered in this work for the following reasons:

- care would be required to maintain driveability under higher power demand of the EHC. E.g. electric driving or boost functions will suffer from limited availability of electric power;

- the heat transfer between the heating element and the catalyst substrate will be limited by the contact surface. Also the material specific heat conduction puts a limitation on how fast heat can enter the TWC and diffuse in radial direction. SimCat uses a $1 \mathrm{D}$ simulation model which is not sufficiently accurate to express this behavior for high power levels. Instead a 2D model is required.
Similar to the situation with ignition retard, the light-off data is translated into a fuel penalty diagram. Most important parameter needed at this point is the fuel equivalent factor $\xi[\mathrm{g} / \mathrm{kWh}$. This equivalence factor describes the additional fuel consumption of the combustion engine when it supplies power to the electric machine to recharge the battery for electric power $P_{e}[\mathrm{~W}]$ taken by the EHC. Similar approaches introducing a fuel equivalent factor have been presented in for example $[7,8]$.

Parameter $\xi$ will be derived from the engine BSFC map. The BSFC map describes the momentary fuel use of the engine given a certain operating point. The minimum value of this map is achieved when the engine enters its sweet spot operating range. Nevertheless, when the engine is running at constant speed and additional torque is requested (e.g. for charging the battery), one should consider the gradient of the BSFC map, rather than the absolute BSFC value, in order to predict the associated extra fuel needed. This is defined as $\xi$ and expresses the change in fuel consumption $[\mathrm{g} / \mathrm{h}]$ for a change in engine workpoint $[\mathrm{kW}]$.

An interesting detail is that the gradient of the engine fuel map with respect to crankshaft torque remains fairly constant over a large operating range, see also [8] for a detailed explanation. Moreover, this gradient comes below the minimum value of the BSFC map. Altogether, $\xi$ can be easily determined when the BSFC map is known.

Owing to energy losses, the power requested from the engine will be higher than the net electric power used by the EHC. The assumptions made necessary about the conversion efficiency from fuel to electric power are shown in Figure 11. For this case study, the efficiency parameters have been selected according to the values indicated in Table 2 . 


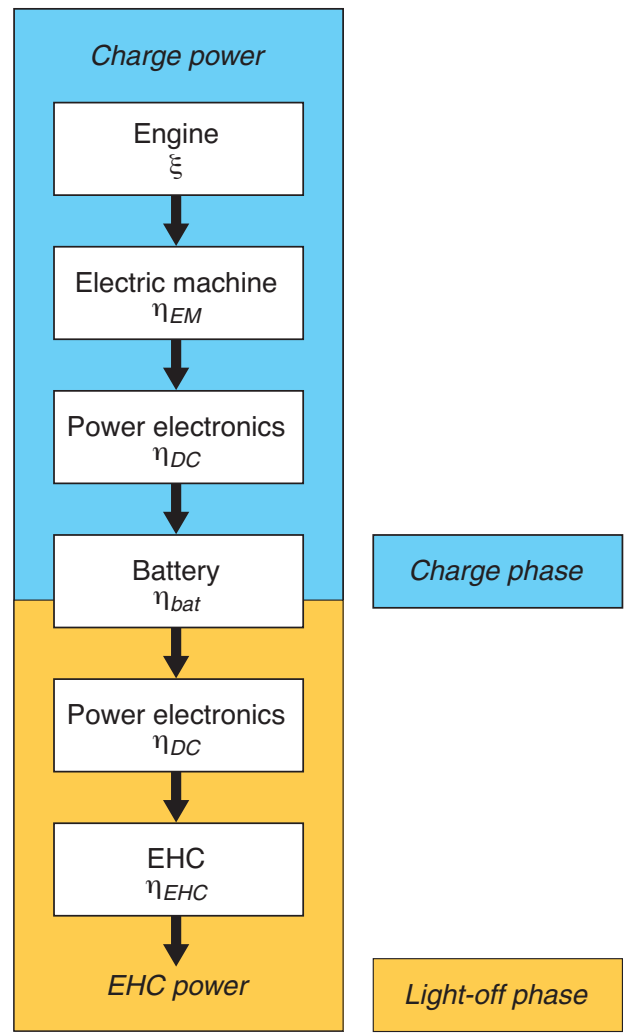

Figure 11

Energy path for EHC function.

As a last step, the total energy request during the light-off period is translated into a momentary fuel cost using the fuel equivalent factor $\xi$. By integrating these fuel costs during light-off time the actual fuel penalty $F_{E}$ emerges:

$$
F_{E}\left(P_{e}\right) \approx \frac{1}{3.6 e 6} \frac{1}{\eta_{E M} \eta_{b a t}\left(\eta_{D C}\right)^{2}} \int_{0}^{t_{L}} \xi P_{e} d t[\mathrm{~g}]
$$

Note that $\eta_{E H C}$ is not visible in (4), since it was already included in the SimCat simulation model. Therefore, the light-off time $t_{L}$ defined in (4) can be directly obtained from Figure 10. The remaining parameters are defined in Table 2 and the resulting fuel penalty is visualized in Figure 12. For convenience, also the results from ignition retard are repeated in Figure 12. It can be seen that the fuel penalty increases proportionally with reduction in light-off time for $P_{e} \leq 500 \mathrm{~W}$.

Besides heat from the EHC, the TWC also receives heat from the engine exhaust gas. However, the contribution from the exhaust gas to heat up the TWC becomes relatively smaller when aiming at short light-off time with the EHC. Consequently, it is expected that the trend for extra fuel penalty when the EHC applies high power levels (i.e. $P_{e}>2.0 \mathrm{~kW}$ ) will continue.
TABLE 2

Selected component parameters

\begin{tabular}{l|c}
\hline Component & Value \\
\hline Battery efficiency $\eta_{\text {bat }}=\eta_{\text {charge }} \times \eta_{\text {discharge }}$ & $92 \%$ \\
\hline Electric machine efficiency $\eta_{\mathrm{EM}}$ & $80 \%$ \\
\hline Power electronics efficiency $\eta_{\mathrm{DC}}$ & $97 \%$ \\
\hline EHC efficiency $\eta_{\mathrm{EHC}}$ & $96 \%$ \\
\hline Fuel equivalent factor $\xi$ & $200 \mathrm{~g} / \mathrm{kWh}$ \\
\hline
\end{tabular}

A TWC with NG engine is very sensitive to water condensation in the aftertreatment system during cold start. Water in the catalyst keeps the catalyst temperature low and hampers the catalytic reactions from taking place. By applying EHC, the catalyst substrate can be rapidly heated and water condensation is prevented. This pays off in large lightoff time reductions. The present SimCat model does include a phenomenological model for water condensation and evaporation. However, this model is validated for ignition retard and not for the situation with the EHC.

Using a traditional hybrid powersplit strategy, it follows that all energy available from regenerative braking will be used for hybrid vehicle operation and not for EHC. Nevertheless, energy from regenerative braking can be used for EHC. If the energy for EHC is recharged into the battery using regenerative braking, the equivalence factor $\xi$ decreases. According to the actual driving cycle and the powersplit strategy, its true value can be determined. Ultimately, $\xi$ becomes zero when regenerative braking supplies all energy requested by EHC.

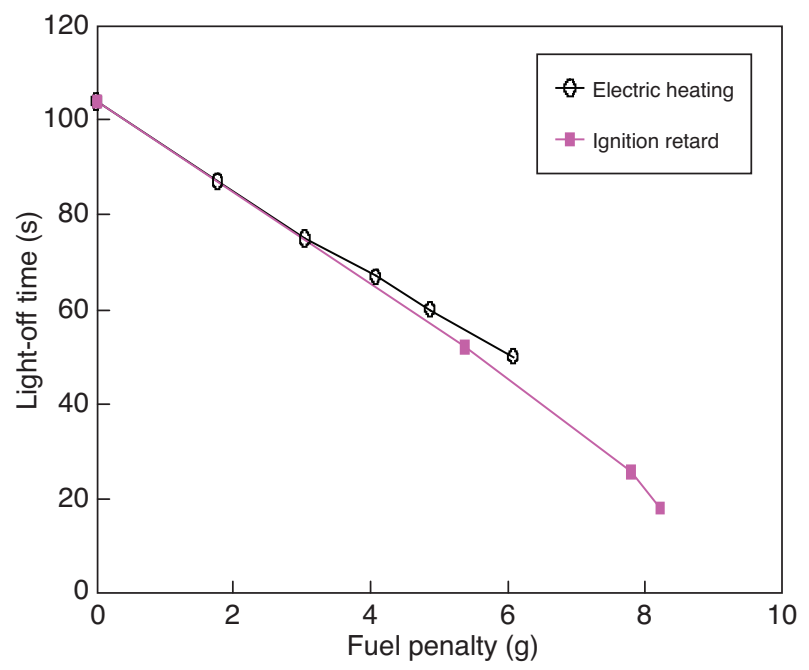

Figure 12

Estimated fuel penalty for EHC. 


\subsection{Comparison}

By analyzing the results from Figure 9 and Figure 12, the IPC concept offers a systematic tool to compare the impact of ignition retard as well as EHC on fuel economy.

It may be concluded that:

- ignition retard provides a significant reduction in light-off time, but also leads to an increase in instantaneous fuel consumption of up to $50 \%$. This is equivalent to $8.2 \mathrm{~g}$ fuel consumption penalty for $86 \mathrm{~s}$ reduction in light-off time;

- electric heating is also a competitive measure for reducing light-off time. In this case study, the fuel penalty is slightly higher than for ignition retard. For a light-off time reduction of $54 \mathrm{~s}$, a fuel penalty of approximately $6.1 \mathrm{~g}$ is indicated with a heating power of $1.5 \mathrm{~kW}$. Compared to the fuel penalty from ignition retard this is an increase of $13 \%$;

- electric heating is effective at lower power levels, while increasing the heating power at higher levels yields additional losses. Note that if the light-off time is already short (e.g. retard is applied), high power is required to achieve small additional gains. This conclusion is supported by other results [9];

- since the fuel penalty for the EHC cannot outscore the fuel penalty for ignition retard, the attractiveness of $\mathrm{EHC}$ will be strongly dependent on the system costs compared with the benefit for other applications such as emission reduction. A comparison on emission reduction as presented in Section 2 needs to be done such that IPC not only decides on energy management, but also includes emission management. This is a topic for further research, which should also consider pre-crank heating (i.e. heating of the EHC becomes active prior to engine start).

\section{CONCLUSIONS}

Due to increasing environmental requirements placed on modern road vehicles, it becomes more important to balance the requirements for efficiency, emissions and costs. This leads to ever increasing system complexity, new analysis techniques and better system control. In order to address this challenge, TNO is developing an approach under the framework of Integrated Powertrain Control.
For stoichiometric Otto engines, light-off time is critical for reaching low tail-pipe emissions, but reducing light-off time is associated with a fuel penalty. The fuel consumption impact of two techniques for reducing the light-off time of a TWC for a hybrid vehicle with an NG engine were studied and compared, using a mix of test and simulation: ignition retard and electric heating.

Further work will be focused on extending the results from an emission perspective. Also the validation of the method under real-world driving cycles is foreseen.

\section{REFERENCES}

1 Foster D., Cloudt R., Willems F. (2008) Towards Integrated Powertrain Control: exploiting synergy between a diesel hybrid and aftertreatment system in a distribution truck, IEEE Intelligent Vehicles Symposium, Eindhoven, June 4-6.

2 Fussey P., Goodfellow C., Oversby K., Porter B., Wheals J. (2001) An Integrated Powertrain (IPT) Model - Stage 2: Systems Integration, Supervisory Control and Simulation of Emissions Control Technology, SAE paper 2001-01-0938.

3 Pannag R. Sanketi, Carlos Zavala J., Hedrick J.K., Wilcutts M., Kaga T. (2006) A Simplified Catalystic Converter Model for Automotive Coldstart Applications with Adaptive Parameter Fitting, 8th Int. Symposium on Advanced Vehicle Control $A V E C$, Taipei, August 20-24.

4 Yamanaka A., Sonoda Y. (2007) Development of the Lexus Hybrid System for High Performance All Wheel Drive Vehicles, 28th International Vienna Engine Symposium, Vienna, April 26-27.

5 Willems F., Cloudt R., Van den Eijnden E., Van Genderen M., Verbeek R., De Jager B., Boomsma W., Van den Heuvel I. (2007) Is closed-loop SCR control required to meet future emission targets? SAE paper 2007-01-1574.

6 Bissett E.J., Oh S.H. (1999) Electrically heated converters for automotive emission control: determination of the best size regime for the heated element, Chem. Eng. Sci. 54, 18, 3957-3966.

7 Guzzella L., Sciarretta A. (2005) Vehicle Propulsion Systems Introduction to Modeling and Optimization, Springer-Verlag, Berlin Heidelberg.

8 Kessels J., Koot M., De Jager B., Van den Bosch P., Aneke N., Kok D. (2007) Energy Management for the Electric Powernet in Vehicles with a Conventional Drivetrain, IEEE T. Contr. Syst. T. 15, 3, 494-505.

9 Holy G., Brueck R., Hirth P. (2000) Improved Catalyst Systems for SULEV Legislation: First Practical Experience, SAE paper 2000-01-0500.

Final manuscript received in July 2009 Published online in February 2010 